\title{
Evolution of the Mobility Gap with Thickness in Hydrogen-Diluted Intrinsic Si:H Materials in the Phase Transition Region and Its Effect on p-i-n Solar Cell Characteristics
}

\author{
R.J. Koval, J.M. Pearce, A.S. Ferlauto, R.W. Collins, and C.R. Wronski \\ The Center for Thin Film Devices at Pennsylvania State University, \\ University Park, PA 16802
}

\begin{abstract}
Insights into the growth processes and evolution of microstructure in intrinsic hydrogenated silicon $(\mathrm{Si}: \mathrm{H})$ films obtained from realtime spectroscopic ellipsometry (RTSE) are extended to the characterization of the optoelectronic properties of the corresponding solar cells. To assess the effects of transition regions from the amorphous to mixed microcrystalline phases, cell structures with and without such regions at different depths in the i-layer from the p-contact have been investigated. Experimental results are presented that clearly demonstrate changes in the mobility gap, $\mathrm{E}_{\mu}$, of the materials as their microstructure evolves with thickness, further supporting the important effect of the hydrogen dilution ratio $\mathrm{R}\left(\mathrm{R} \equiv\left[\mathrm{H}_{2}\right] /\left[\mathrm{SiH}_{4}\right]\right)$ on the transition between the amorphous and microcrystalline phases. Light $\mathrm{J}-\mathrm{V}$ characteristics at room temperature and dark $\mathrm{J}-\mathrm{V}$ characteristics at different temperatures were measured on $\mathrm{p}(\mathrm{a}-\mathrm{SiC}: \mathrm{H}: \mathrm{B})-\mathrm{i}(\mathrm{Si}: \mathrm{H})-\mathrm{n}(\mu \mathrm{c}-\mathrm{Si}: \mathrm{H}: \mathrm{P})$ solar cell structures with i-layers of different thicknesses and $\mathrm{R}$ values. The mobility gaps of both the amorphous and microcrystalline intrinsic-layer materials as well as those of the transition layers are obtained from dark $\mathrm{J}(\mathrm{V}, \mathrm{T})$ measurements. Using numerical simulation, both the light and the dark J-V characteristics are self-consistently modeled assuming sharp changes in the mobility gaps at the intrinsic layer transition thicknesses determined by RTSE.
\end{abstract}

\section{INTRODUCTION}

Over the past decade, the deposition of a-Si:H i-layers from hydrogen diluted silane has been established as a means of improving the performance and stability of a-Si:H based $\mathrm{p}-\mathrm{i}-\mathrm{n}$ and $\mathrm{n}-\mathrm{i}-\mathrm{p}$ solar cells [1,2]. It is found that both the materials and the solar cells prepared with $\mathrm{H}_{2}$-dilution of $\mathrm{SiH}_{4}$ exhibit improved optoelectronic properties and degradation kinetics distinctly different from their counterparts prepared without $\mathrm{H}_{2}$-dilution. They exhibit less degradation under 1 sun illumination and reach a degraded steady state in significantly shorter times [3]. The use of such cells as the wide bandgap component of multi-junction devices imposes requirements on their bandgaps and thicknesses brought about by the required matching of the currents generated in the component cells. Therefore there is great interest in using hydrogen dilution to vary the gap of Si:H intrinsic layers while at the same time optimizing the stabilized performance by adjusting their thicknesses.

The recently established evolution of the microstructural and optical properties with thickness for the "hydrogen diluted" materials [4], coupled with the strong effect that the substrate material imposes on such properties for the overdeposited layers $[5,6]$ greatly complicates the optimization of stable a-Si:H based solar cells. The complexity is further exacerbated in cases of cell structures optimized using a twostep i-layer process in which the $\mathrm{p} / \mathrm{i}$ interface region has a higher hydrogen dilution ratio $\mathrm{R}$ $\left(\mathrm{R} \equiv\left[\mathrm{H}_{2}\right] /\left[\mathrm{SiH}_{4}\right]\right)$ than that of the bulk i-layer $[4,19]$. Furthermore, the inhomogeneity and anisotropic nature of these evolving materials give rise to difficulties in correlating thin film material properties with device characteristics due to the inherent differences between the transverse carrier transport in the cell configuration and the in-plane transport in the standard coplanar configuration [7]. The realtime in-situ studies of Si:H film growth which established an evolutionary phase diagram [8], together with the characterization and numerical modeling of the various cell structures described in this work, provides a unique method of circumventing these problems and allows reliable correlations to be made between the intrinsic material properties and corresponding cell characteristics. 


\section{EXPERIMENTAL DETAILS}

The specular $\mathrm{SnO}_{2} / \mathrm{p}-\mathrm{a}-\mathrm{SiC}: \mathrm{H}: \mathrm{B} / \mathrm{i}-\mathrm{Si}: \mathrm{H} / \mathrm{n}-\mu \mathrm{c}-\mathrm{Si}: \mathrm{H}: \mathrm{P} / \mathrm{Cr}$ solar cells were deposited in a multichamber rf-PECVD system at $200^{\circ} \mathrm{C}$ under previously described conditions [9]. To minimize the possibility of shunt currents in the dark J-V characteristics at low forward bias, small device areas were defined by evaporating $2 \mathrm{~mm}^{2} \mathrm{Cr}$ electrodes on the p-i-n structure and subsequently reactive ion etching the exposed $\mathrm{n}-\mu \mathrm{c}-\mathrm{Si}: \mathrm{H}$ to isolate the cells. The dark J-V characteristics of the cells were measured over a temperature range from $25-125^{\circ} \mathrm{C}$. The evolution of the microstructure in the various $\mathrm{Si}: \mathrm{H}$ layers was characterized using a rotating compensator multichannel ellipsometer [10]. The cell characteristics were modeled using AMPS (Analysis of Microelectronic and Photonic Structures) simulation code [11]. The gap state distribution used for the a-Si:H materials includes charged defects and is similar to that used in the analysis of results in the detailed studies of a-Si:H films [12]. The amorphous-to-(mixed-phasemicrocrystalline) $[a \rightarrow(a+\mu c)]$ transitions were modeled as abrupt changes in the mobility gap, with the band discontinuities split equally between the valence and conduction bands [13], and midgap defect densities of $10^{16} \mathrm{~cm}^{-3}$ for the $\mu \mathrm{c}-\mathrm{Si}: \mathrm{H}[14]$.

\section{RESULTS AND DISCUSSION}

Effects on performance and stability of the thickness-dependent $a \rightarrow(a+\mu c)$ phase transitions in the i-layers of Si:H based solar cells have been previously reported [9]. The initial fill factors (FF) of cells prepared with i-layers from $1100 \AA$ to $1 \mu \mathrm{m}$, a thickness range over which such transitions occur, are shown in Fig. 1 for cells having $0 \leq \mathrm{R} \leq 20$ but otherwise identical deposition conditions. At a thickness of $1100 \AA$, the initial FF of all cells are virtually the same irrespective of R. For $R=0$, where no phase transition occurs over the entire thickness range of the i-layer, the FF decreases as expected in a manner closely matching that of the numerical simulation for a uniform homogeneous i-layer. However, for the cells prepared with dilution, there are clearly discernible thickness-dependent deviations from the $\mathrm{R}=0$ FFs that can be attributed to the phase transitions in the bulk layers as indicated by the phase diagram developed for Si:H film deposition on amorphous film surfaces [8]. It is important to note here that the phase transition in the Si:H materials is not abrupt, but passes through an amorphous + microcrystalline $(\mathrm{a}+\mu \mathrm{c})$ mixed-phase region, in which the microcrystallites embedded in the amorphous matrix increase in in-plane scale with increasing thickness at a rate that depends on $\mathrm{R}$.

The mobility gap $\left(\mathrm{E}_{\mu}\right)$ of the bulk i-layers and their transition regions plays a key role in transport and collection of photogenerated carriers. In p-i-n cells whose characteristics are dominated by the bulk, the dark current characteristics are very sensitive to the i-layer $E_{\mu}$. This is illustrated in Fig. 2a with the forward dark J-V characteristics of p-i-n cells having $4000 \AA$ thick $\mathrm{R}=0$ and $\mathrm{R}=10$ i-layers (shown as symbols). The J-V characteristics exhibit the classical exponential diode behavior with a reverse

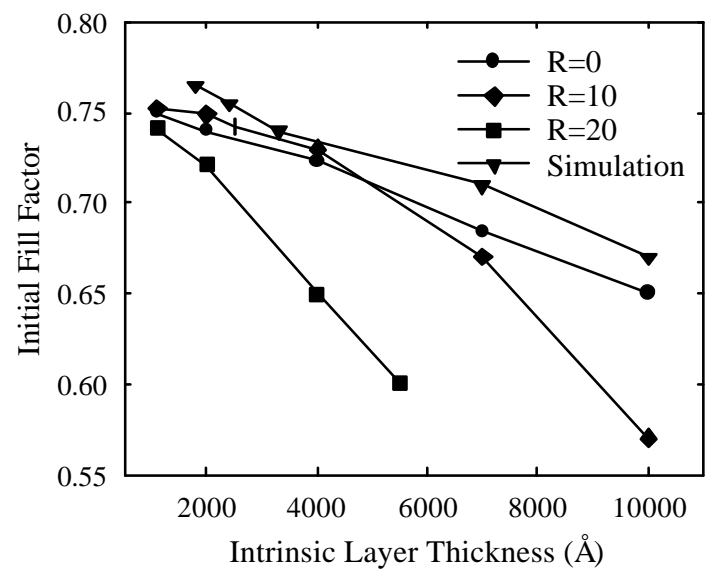

Figure 1. Dependence of initial fill factor of $p-i-n$ cells on the intrinsic layer thickness for $\mathrm{R}=0,10$, and 20. For comparison, simulation results for an $\mathrm{R}=0$ structure having a homogeneous i-layer are also included. 
saturation current density $\left(\mathrm{J}_{\mathrm{o}}\right)$ that can be obtained from the intercept of the linear region of this semilog plot. The $R=0$ and $R=10$ materials have the same densities of midgap states $\left(D_{o}\right)$ and $E_{\mu}$ values of $1.80 \mathrm{eV}$ and $1.87 \mathrm{eV}$, respectively, as determined from internal photoemission measurements [15]. The sensitivity of the J-V characteristics to $E_{\mu}$ is reflected in the values of $J_{0}$, which differ by approximately one order of magnitude, and the excellent agreement with simulation results (shown as solid lines) obtained using the corresponding values of $E_{\mu}$. It is found that reliable $E_{\mu}$ values can be obtained from the dependence of $J_{o}$ on temperature in $\mathrm{p}-\mathrm{i}-\mathrm{n}$ cells where the dark currents are dominated by recombination-generation $(\mathrm{R}-\mathrm{G})$ in the bulk i-layer $[16,17,18]$. In this case, the dependence of $J_{o}$ on the i-layer mobility gap is:

$$
\frac{J_{o}}{T^{3}}=A \exp \left(\frac{-E_{\mu}}{2 k T}\right)
$$

where $\mathrm{A}$ is a temperature-independent pre-factor and $\mathrm{E}_{\mu}$ is the i-layer mobility gap. The dependences of $\mathrm{J}_{\mathrm{o}} / \mathrm{T}^{3}$ on temperature for the cells in Fig. 2a are shown in Fig. 2b, where the well-defined slopes yield values of $E_{\mu}$ that are in excellent agreement with the values quoted above.

The correlations among carrier recombination kinetics in the bulk i-layer, $\mathrm{J}_{0}$, and $\mathrm{E}_{\mu}$ established for $\mathrm{p}$-i-n cells with homogeneous i-layers have been extended to include the more complicated case of cells with evolving i-layers. This effort was carried out by studying a series of $\mathrm{p}-\mathrm{i}-\mathrm{n}$ cells each with a total i-layer thickness of $4000 \AA$ An $R=40$ layer was incorporated at the p/i interface of each cell, leading to a two-step i-layer with $R=40$ layer thicknesses ranging from $100 \AA$ to $400 \AA$. The cells exhibit optimum performance when the $\mathrm{R}=40$ interface layer thickness is $200 \AA$, whereas with increasing thickness above this optimum both $\mathrm{FF}$ and $\mathrm{V}_{\text {oc }}$ decrease [19]. Insights into the electronic properties of the transition material from amorphous to mixed-phase $\mathrm{Si}: \mathrm{H}$ and then to single-phase $\mu \mathrm{c}-\mathrm{Si}: \mathrm{H}$ that give rise to deleterious effects on cell performance can be obtained from the dark $\mathrm{J}-\mathrm{V}$ characteristics of the cells as shown in Fig. 3a. The increase in carrier R-G in the vicinity of the phase transition region can be directly inferred from the systematic increase of the dark currents in the exponential region as the $\mathrm{R}=40 \mathrm{Si}: \mathrm{H}$ layer thickness increases from 100 to $400 \AA$ and traverses the phase boundary. The increase by two orders of magnitude in the room temperature value of $\mathrm{J}_{\mathrm{o}}$ clearly indicates a large increase in R-G currents that can be attributed primarily to changes in the mobility gap. This is evident from Fig. $3 \mathrm{~b}$ wherein plots of $\mathrm{J}_{\mathrm{o}} / \mathrm{T}^{3}$ versus $\left(2 \mathrm{kT}^{-1}\right.$ are shown for the results in Fig. 3a. Because the value of $1.88 \mathrm{eV}$ obtained from the cell with the $200 \AA \mathrm{R}=40$ interface layer matches that for the bulk homogeneous i-layer (see Fig. 2b), any decreases in activation energies from this value with increasing interface layer thickness can be used to obtain the changes in the effective mobility gap that occur across the phase transition. The decreases to
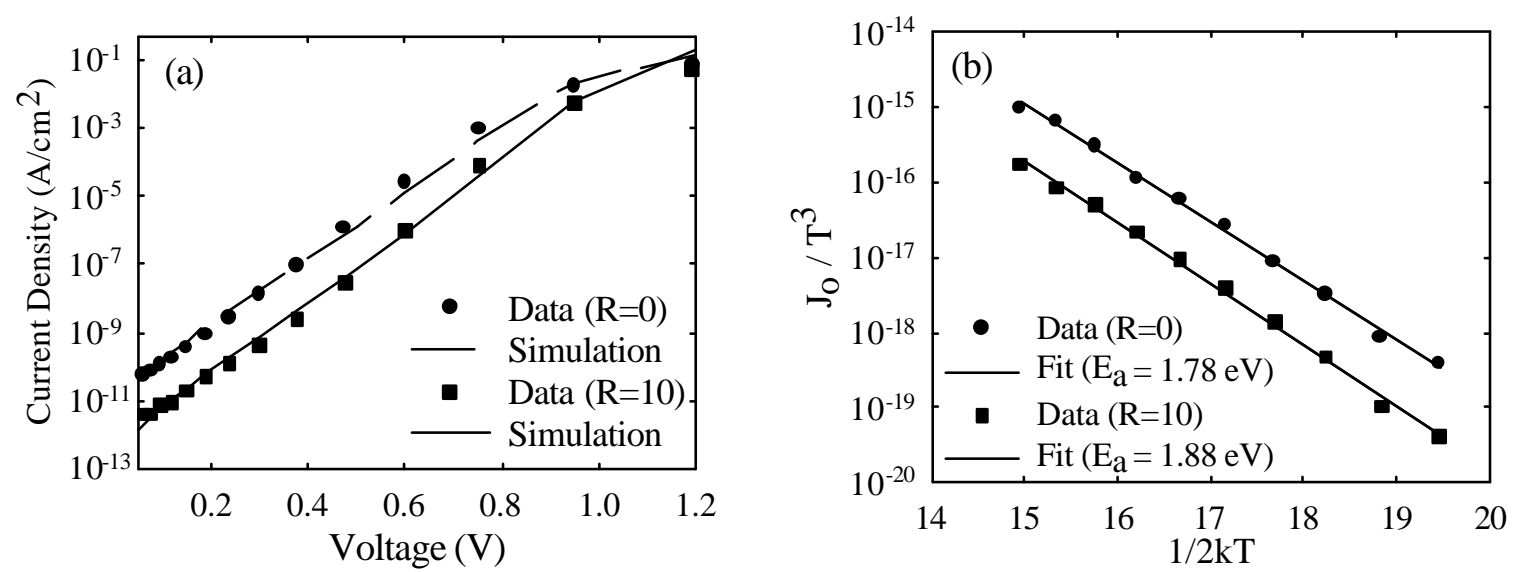

Figure 2. (a) Experimental dark $J-V$ characteristics (symbols) of $R=0$ and $R=10$-i-n cells having $4000 \AA$ A thick i-layers and equivalent contact layers. AMPS simulation results are shown as solid lines. (b) Thermal activation plots of $\mathrm{J}_{\mathrm{o}} / \mathrm{T}^{3}$ for the cells shown in (a). The symbols are experimental results and the solid lines are exponential fits used to extract $\mathrm{E}_{\mu}$. 

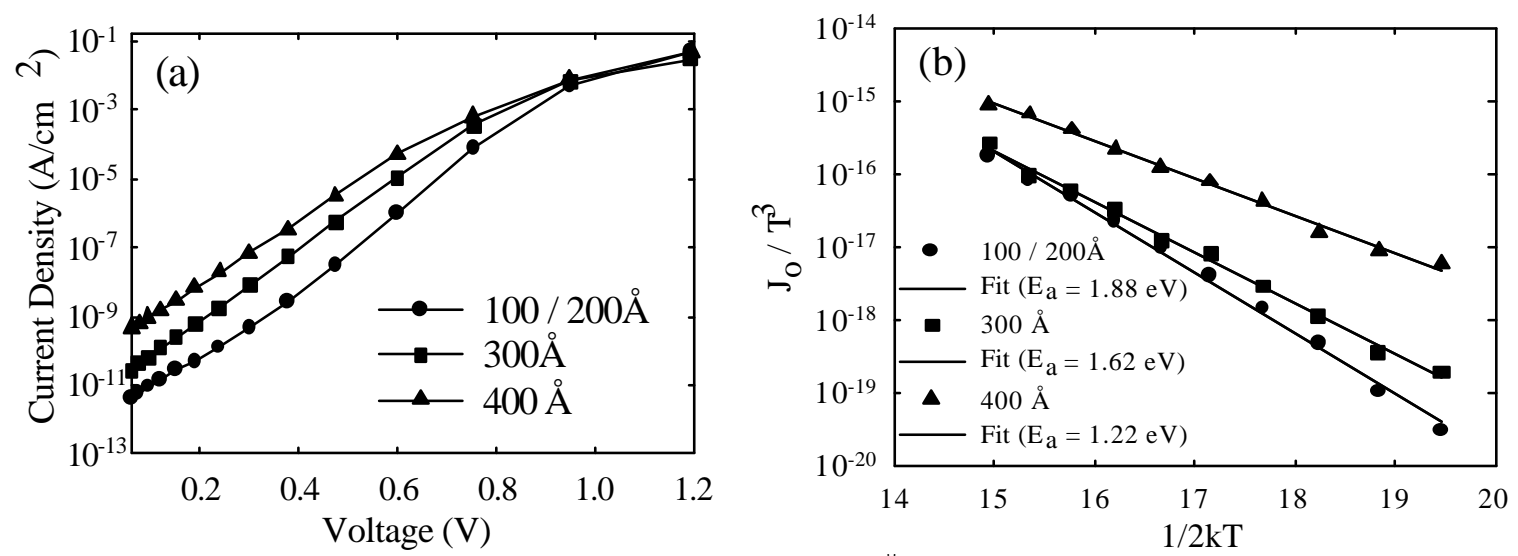

Figure 3. (a) Experimental dark $J-V$ characteristics of $4000 \AA ̊ n p-i-n$ cells having $R=10$ bulk i-layers and different thickness $\mathrm{R}=40 \mathrm{p} / \mathrm{i}$ interface layers. (b) Thermal activation plots of $\mathrm{J}_{\mathrm{o}} / \mathrm{T}^{3}$ for the cells shown in (a). The symbols are experimental results and the solid lines are exponential fits used to extract $\mathrm{E}_{\mu}$.

$1.66 \mathrm{eV}$ for the $300 \AA$ Anterface layer and to $1.22 \mathrm{eV}$ for the $400 \AA$ Alayer indicate that over a thickness of $200 \AA$ A there is a transition from the amorphous phase to a material having a mobility very close to that of bulk microcrystalline $\mathrm{Si}: \mathrm{H}$. However, the fact that the value of $\mathrm{J}_{\mathrm{o}}$ increases by only two orders of magnitude across the phase transition is a clear indication that the microcrystalline phase does not extend throughout the i-layer but that the subsequent growth of the $\mathrm{R}=10$ material proceeds in the amorphous phase as has been substantiated by RTSE studies [8].

To obtain additional insights into the transitions as well as their effect on cell characteristics, studies were carried out on a cell in which a $400 \AA \mathrm{R}=40 \mathrm{p} / \mathrm{i}$ interface (similar to that described above) was followed by an $\mathrm{R}=20$ bulk i-layer region (referred to here as cell $\mathrm{C}$ ). The characteristics of this cell are compared with those of the optimized structure described above having a $200 \AA \mathrm{R}=40 \mathrm{p} / \mathrm{i}$ interface and an $\mathrm{R}=10$ bulk region (referred to as cell $\mathrm{A}$ ). The comparison also includes a cell deposited with a one-step $\mathrm{R}=20$ i-layer (referred to as cell $\mathrm{B}$ ). While cell A has a relatively homogeneous amorphous ilayer, ellipsometry studies show that the $\mathrm{a} \rightarrow(\mathrm{a}+\mu \mathrm{c})$ transition in the $\mathrm{R}=20$ layer deposited on an amorphous film occurs after an accumulated film thickness of approximately $1000 \AA$ Similar studies have also demonstrated that the growth of the same $\mathrm{R}=20$ layer on an $\mathrm{R}=40$ layer that has traversed the phase boundary proceeds in the microcrystalline phase so that the i-layer is fully microcrystalline with the exception of the initial $400 \AA$. In fact, the first $200 \AA$ of the i-layer of cell $\mathrm{C}$ is amorphous whereas the next $200 \AA$ is mixed-phase $(\mathrm{a}+\mu \mathrm{c})$. The experimental $\mathrm{J}-\mathrm{V}$ results at room temperature are shown in Figs. $4 \mathrm{a}$ and $4 \mathrm{~b}$ under 1 sun illumination and in the dark, respectively, for cells $\mathrm{A}, \mathrm{B}$, and C. It can be seen in Fig. 4a that the FF and $V_{o c}$ are the highest for cell $A$ since the thickness and $R$ values in the two step ilayer are chosen so that protocrystallinity [i.e., Si:H deposition just on the amorphous side of the $\mathrm{a} \rightarrow(\mathrm{a}+\mu \mathrm{c})$ phase boundary] is maintained. The cell performance becomes progressively worse for cells $\mathrm{B}$ and $\mathrm{C}$ as the position of the phase boundary in the i-layer approaches the p-contact (indicated by the direction of the arrows).

This drop in cell performance is attributed to narrow gap material in the i-layer of cells B and C whose presence is reflected in the dark $\mathrm{J}-\mathrm{V}$ characteristics as shown in Fig. $4 \mathrm{~b}$. In p-i-n structures most of the carrier recombination occurs in a narrow region, approximately halfway between the $\mathrm{p}$ - and $\mathrm{n}$ contacts at low forward bias. At higher forward bias, this region extends toward both contacts. Fig. 5 shows such a bias-dependence and spatial non-uniformity of the carrier recombination rates in a p-i-n cell with a homogeneous amorphous i-layer. Inflection points in the dark $\mathrm{J}-\mathrm{V}$ characteristics observed in Fig. 

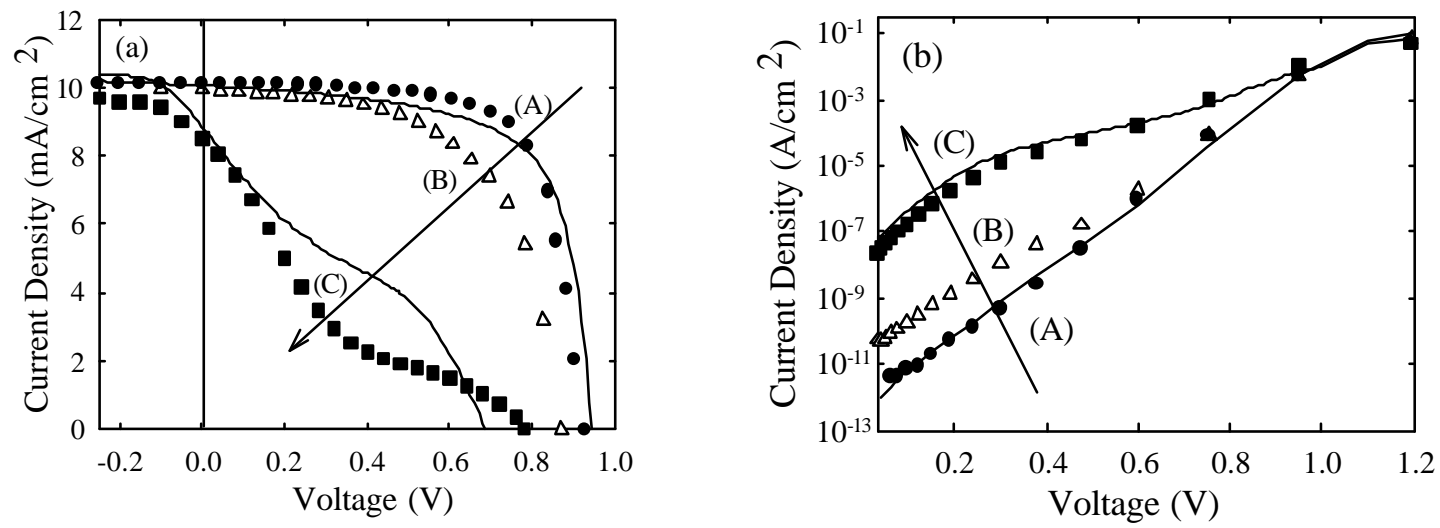

Figure 4. Experimental data (symbols) and simulations (solid lines) for the $\mathrm{J}-\mathrm{V}$ characteristics of cells A, B, and C measured at room temperature (a) under 1 sun illumination and (b) in the dark.

Direction of the arrows indicate decreasing distance between the $a \rightarrow(a+\mu c)$ transition and p-contact.

$4 \mathrm{~b}$ can thus be explained by the large contribution of the narrow gap material to the recombination currents at low forward bias. The eventual merging of the currents in cells B and C with that of cell A at higher forward bias in Fig. $4 \mathrm{~b}$ is due to a shift of the recombination from the bulk i-layer to the vicinity of the contact layer regions that are similar for all three cells. The forward bias voltage at which the dark current of cell $\mathrm{C}$ merges with that of cell $\mathrm{A}$ is larger than the corresponding bias for cell $\mathrm{B}$. This behavior occurs because the phase boundary in cell $\mathrm{C}$ is closer to the $\mathrm{p}$-layer so that the carrier recombination in the narrow gap material dominates over a larger voltage range. The simulation result shown in Fig. $4 \mathrm{~b}$ (solid line) was carried out for cell C assuming a $400 \AA$ wide gap Si:H layer with the remainder of the ilayer (3600 $\AA$ ) as a narrow gap $\mu \mathrm{c}$-Si:H material having a mobility gap of $1.15 \mathrm{eV}$. The latter value is obtained experimentally from plot of $\mathrm{J}_{0} / \mathrm{T}^{3}$ vs. $(2 \mathrm{kT})^{-1}$ for cell $\mathrm{C}$. The use of an abrupt change in $\mathrm{E}_{\mu}$ is justified by the data shown in Fig. $3 \mathrm{~b}$ as well as by RTSE. Both results suggest that the transition from the amorphous phase to a fully coalesced microcrystalline phase in the $\mathrm{R}=40$ film occurs over a thickness of only a few hundred angstroms.

The large decreases of the FF in cells B and $\mathrm{C}$ are a direct consequence of the phase transitions. The higher photo-carrier densities generated in the $\mu \mathrm{c}-\mathrm{Si}$ :H portion of the i-layer lead to a collapse of the electric field in that region in order to maintain current continuity across the entire i-layer. As a consequence, most of the voltage drop then occurs across the amorphous region. The weaker average field across the i-layer results in the anomalous inflection point in the light $\mathrm{J}-\mathrm{V}$ characteristics as seen in Fig. 4a, with the effect becoming more pronounced as the phase transition approaches the p-contact. Such characteristics could only be modeled for i-layers consisting of two distinctly different layers - a widegap amorphous layer and a narrow gap microcrystalline one. Such an approach was also successful

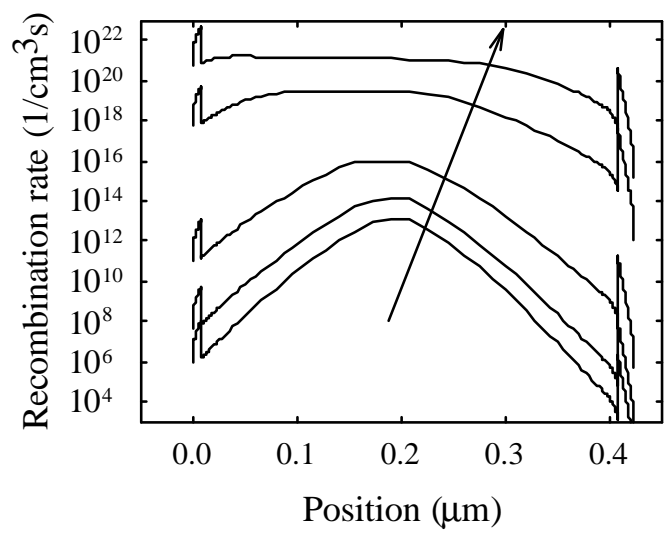

Figure 5. Recombination profiles in a typical aSi:H p-i-n solar cell in the dark having a homogeneous i-layer. Different values of forward bias voltage are shown $(\mathrm{V}=0.1,0.2,0.4,0.8,1.0 \mathrm{~V})$ with the direction of the arrow indicating increasing forward bias voltage. 
in simulating the results of earlier studies of intrinsic $\mu \mathrm{c}-\mathrm{Si}: \mathrm{H}$ growth on $\mathrm{p}-\mathrm{a}-\mathrm{SiC}: \mathrm{H}$ [20]. The results of the simulation for cell $\mathrm{C}$ is shown as a solid line in Fig. 4a, where the less than perfect fit is probably due to the necessary oversimplification of the highly anisotropic microcrystalline material when a onedimensional simulator such as AMPS is being used.

\section{CONCLUSIONS}

Correlating a-Si:H material properties with cell characteristics has been an ongoing challenge. The evolution of the growth of the $\mathrm{Si}: \mathrm{H}$ films prepared with $\mathrm{H}_{2}$-dilution from an amorphous phase to the highly anisotropic microcrystalline phase makes the task even more difficult. Hence cell optimization requires a systematic approach such as that described here. In this unique approach, $p$-i-n cells were selfconsistently modeled assuming a change in the i-layer mobility gap at the thickness determined by RTSE, whereby the values of the mobility gaps are obtained from measurements on the actual $\mathrm{p}$-i-n structures. As a result, meaningful correlations can be made between the materials and solar cell characteristic s since the uncertainties associated with the initial nucleation and subsequent growth of Si:H films on different substrate materials are eliminated. Furthermore, the simulations corroborate the thickness position of the phase boundary as determined by RTSE. The insights provided here into the transition from protocrystalline $\mathrm{Si}: \mathrm{H}$ to mixed-phase $\mathrm{Si}: \mathrm{H}$ and then to single-phase $\mu \mathrm{c}-\mathrm{Si}: \mathrm{H}$ are of critical importance to the engineering of cell structures with high performance and improved stability.

\section{REFERENCES}

1. M. Bennett, K. Rajan, and K. Kritikson, Conf. Record of the $23^{\text {rd }}$ IEEE PVSC, (IEEE, NY 1993), p. 845.

2. J. Yang, X. Xu, and S. Guha, Mater. Res. Soc. Symp. Proc. 336, 669 (1994).

3. Y. Lee, L. Jiao, H. Liu, Z. Lu, R.W. Collins, and C.R. Wronski, Conf. Record of $25^{\text {th }}$ IEEE PVSC, (IEEE, NY 1996), p. 1165.

4. J. Koh, Y. Lee, H. Fujiwara, C.R. Wronski, and R.W. Collins, Appl. Phys. Lett. 73, 1526 (1998).

5. R.W. Collins, and B.Y. Yang, J. Vac. Sci. Tech. B 7, 1155 (1989).

6. J. Koh, A.S. Ferlauto, P.I. Rovira, R.J. Koval, C.R. Wronski, and R.W. Collins, Journal of NonCrystalline Solids 266-269, 43 (2000).

7. J. Kocka, A. Fejfar, P. Fojtik, K. Luterova, I. Pelant, B. Rezek, H. Stuchlikova, J. Stucklik, and V. Svrcek, Solar Energy Materials and Solar Cells 66, 61 (2001).

8. A.S. Ferlauto, P.I. Rovira, R.J. Koval, C.R. Wronski, and R.W. Collins, Mater. Res. Soc. Symp. Proc. (2000, in press).

9. R.J. Koval, J. Koh, Z. Lu, Y. Lee, L. Jiao, R.W. Collins, and C.R. Wronski, Mater. Res. Soc. Symp. Proc. 557, 263 (1999).

10. R.W. Collins, I. An, H. Fujiwara, J. Lee, Y. Lu, J. Koh, and P.I. Rovira, Thin Solid Films 313, 18 (1998).

11. P.J. McElheny, J.K. Arch, H.S. Lin, and S.J. Fonash, J. Appl. Phys. 64, 1254 (1988).

12. L. Jiao, S. Semoushikina, Y. Lee, C.R. Wronski, Mater. Res. Soc. Symp. Proc. 97, 233 (1997).

13. H. Wagner, personal communication.

14. F. Finger, J. Muller, C. Malten, and H. Wagner, Phil. Mag. B 77, 805 (1998).

15. C.R. Wronski, S. Lee, M. Hicks, and S. Kumar, Phys. Rev. Lett. 63, 1420 (1989).

16. M.S. Bennett and R.R. Arya, Solar Cells 18, 289 (1986).

17. H. Zhu and S. Fonash, Mater. Res. Soc. Symp. Proc. 507, 395 (1998).

18. J. Pearce, R. Koval, A. Ferlauto, R.W. Collins, C.R. Wronski, J. Yang, and S. Guha, Appl. Phys. Lett. 77, 3090 (2000).

19. R.J. Koval, J. Pearce, A. Ferlauto, R.W. Collins, and C.R. Wronski, Conf. Record of the $28^{\text {th }}$ IEEE PVSC, (2000, in press).

20. F. Siebke, S. Yata, Y. Hishikawa, and M. Tanaka, Mater. Res. Soc. Symp. Proc. 507, 517 (1998). 